\title{
A new technique for recovering energy in thermally coupled distillation using vapor recompression cycles
}

\author{
Miguel A. Navarro-Amorós, Rubén Ruiz-Femenia, José A. Caballero. \\ Department of Chemical Engineering, University of Alicante., Ap Correos 99, 03080, \\ Alicante, Spain
}

\begin{abstract}
Costs of chemical processes are often dominated by separation costs. Between different separation techniques, distillation is the most important and commonly used in all chemical and petrochemical industries. Distillation handles more than $90 \%$ of separations and this trend seems unlikely to change in the near future. A renew interest in Thermally Coupled Distillation (TCD) appeared, in the last 15-20 years, due to the important potential savings in energy: typical values around 10 to $50 \%$ has been reported compared with conventional distillation sequences. Although, it has been proved that fully thermally coupled system are arrangement that requires the minimum energy in a sequence of columns, it is possible to identify situations in which some column sections are operating far away from the optimal conditions. Typically, there are a significant excess of vapor/liquid flow which is transferred from one to another section inside a distillation column increasing utilities and capital cost of TCD. This suboptimal situation can be solved introducing an intermediate reboiler/condenser to provide extra vapor/liquid needed in some section of TCD. Alternatively, it is possible to extract some liquid/vapor and consider it as an utility stream that can be used elsewhere in the plant. This paper presents an interesting alternative to solve these situations consisting on implement a vapor compression cycle using this extra vapor/liquid stream. This new arrangement gets an extra saving in energy around $20-30 \%$ compared with conventional TCD columns.

Different examples, including heat and cold recovery cases, are presented. Furthermore in each example, all possibilities of distillation (direct, indirect and Petlyuk distillation) with and without vapor recompression cycle (VRC) are compared to ensure that this approach provides the best results
\end{abstract}




\section{Introduction}

Nowadays, we live in a society where any activity, whether work or leisure, requires the consumption of large amounts of energy. Approximately, global energy consumption is estimated at 16 TW, and it is expected that this increase by 53\% in next 30 years (EIA 2011). One of the areas in which it can be advanced more, especially in industries, is the improvements of energy efficiency. Energy consumption in the industrial sector represents approximately $28 \%$ of global energy consumption. Within this sector, the chemical industry accounts for $20 \%$ approximately. If it perform a simple calculation of percentages, the chemical industries consumes about the $5.6 \%$ of the total energy consumed in the world (about 0.90 TW/year).

However, when the energy consumption of the chemical industry is analyzed, it checks that separation processes involves the highest energy cost. Between the different separation techniques, distillation is the most important and commonly used in all chemical and petrochemical industries. Distillation handles more than 90\% of separations (Humphrey 1995) and this trend seems unlikely to change in the near future. Mix et al. (Mix et al. 1978) calculated that distillation processes consumes about the $60 \%$ of the total energy consumption in the chemical and petrochemical industry. In conclusion, it is estimated that only distillation processes consumes about the 3\% of global energy (Humphrey and Siebert 1992; Engelien and Skogestad 2004). Only in USA, the energy cost of the distillation processes is equivalent to 54 million tons of crude oil. Therefore, any energy saving achieved in the distillation processes will be an important energy saving globally.

The reason for which the distillation consumes large amounts of energy is that the process is highly inefficient. This is illustrated by the fact that the heat (used as separating agent) is conventionally provided in the reboiler where temperature of the process is maximum $\left(T_{B}\right)$, then heat is removed in the condenser where temperature is minimum $\left(T_{D}\right)$. This characteristic produces that the heat recovered in the condenser cannot be reused for heating other areas thereof distillation unit. Actually, the heat is degraded in the temperature $T_{B}-T_{D}$, this is a consequence of thermodynamic inefficiency of the distillation process.

The major source of inefficiency is due to the irreversible mixture of non-identical streams along the column. In conventional columns (a column with a single feed, distillate and bottoms as products, a condenser and a reboiler), products with intermediate volatilities often reach a maximum concentration at an intermediate plate of the column, and then decrease their concentration in the products (distillate and bottoms) to satisfy the overall material balance. This backmixing affects separation efficiency. Other potential source of inefficiency is the differences between the feed composition and the liquid composition that reaches to the feed plate (even after having optimized the location of the feed plate). And finally, the inefficiency associated with 
the backmixing in the condensers and reboilers. In fact, the overall thermodynamic efficiency of a conventional distillation is around 5-20\% (Humphrey et al. 1991; De Koeijer and Kjelstrup 2000).

To improve the thermal efficiency of a distillation column, various methods, such as intercoolers-interheaters, heat pumps, secondary reflux and vaporization, and multiple-effect columns, have been explored. Basically, the idea is to reduce the external energy inputs by effectively utilizing the heat energy from the distillation units and to distribute the heat more uniformly along the length of the columns.

An excellent review which discusses the different energy-efficient distillation techniques was presented by Jana (Jana 2010). Few of the heat integration arrangements for distillation systems are:

(i) Heat pump-assisted distillation columns, the overhead vapor is compressed and then used as a heating medium in the bottom reboiler

(ii) Multi-effect distillation columns, the hot distillate vapor stream may be thermally coupled with the next column bottom liquid stream in the reboiler

(iii) Heat integrated distillation columns, the rectifying and stripping sections are internally coupled through heat exchangers. A compressor and a throttling valve are installed between the two sections for maintaining the driving force

(iv) Divided wall distillation columns (DWC), a ternary mixture can be distilled into pure product streams with only one distillation structure, one reboiler and one condenser. Obviously, this reduces the cost of separation

It is proven that the heat integration leads to a significant improvement in energy efficiency with reducing the reboiler and condenser duties. By proper process design, even sometimes, there is no need of any bottom reboiler and/or reflux condenser for a heat integrated distillation unit.

A renew interest in Thermally Coupled Distillation (TCD) appeared in, say the last 15-20 years, due the important potential savings in energy: typical values around 10 to $50 \%$ has been reported (Ruud 1992; Fidkowski and Agrawal 2001; Caballero and Grossmann 2006) when compared with conventional distillation sequences. Although it has been proved that fully thermally coupled systems are the arrangements that require the minimum energy in a sequence of columns (Halvorsen and Skogestad 2003) it is possible to identify situations in which some column sections are operating far away the optimal conditions.

This paper presents an alternative configuration of heat pump-assisted TCD columns. This new alternative can be applied on thermally coupled distillation columns that some column sections are operating far away from the optimal conditions, saving important amounts of 
energy. Finally, different examples are presents which illustrate the methodology used and the results obtained.

\section{Motivation}

As has been mentioned, the thermally coupled distillation (TCD) gets the lowest energetic requirements in a given sequence of distillation columns (Halvorsen and Skogestad 2003). However, there are many cases where some of the sections of the TCD column operates far from optimum conditions, which means that energy consumptions are not optimal (at least in comparison with the conventional columns), This is due to the intrinsic characteristics of the TCD column.

On a practical or industrial level, thermally coupled distillation can be developed as a divided wall distillation column (DWC), which is thermodynamically equivalent to a Petlyuk configuration column (Petlyuk et al. 1965). For the sake of simplicity, but without losing generality, we will focus on the special case of a three component Petlyuk configuration or its thermodynamically equivalent Divided Wall Column (DWC). It will be evident that the extension to other thermally coupled configurations with more complex arrangements is straightforward.

The simulation of a DWC or its equivalent Petlyuk configuration can be carried out by decomposing in their three separation tasks. Each one of these tasks can be simulated as a conventional distillation column (Figure 1a). First of all, the characteristics ( $n^{\circ}$ of trays, feed trays, diameters,...) of the Petlyuk column must be calculated in order to study its correct behavior. To do that, each one of the conventional columns are optimized independently. Once the columns have been optimized, columns are connected using different thermal coupling. The condenser of column 1 is substituted by two streams, one composed by vapor at its dew point and the other stream composed by liquid at its bubble point. The reboiler of column 1 is substituted using the same method. And finally the reboiler of column 2 and condenser of column 3 are eliminated by connecting both columns (Figure $1 \mathrm{~b}$ ). Thus Petlyuk configuration columns (Figure 1c) and DWC (Figure 1d) are simulated and configured.

When a Petlyuk column is simulated, it is evident that the mass balance must be satisfied in all couplings. While the couplings between columns 1 and 2 with column 3 are produced by side stream extraction, the connection between the column 2 with column 3 is produced by direct binding of both columns. This fact makes that both columns must operate in a similar internal flows interval not to change their behavior and configuration.

$$
v_{2}^{C 2}=v_{1}^{C 3}
$$

This situation rarely occurs. But usually, from the optimized columns the vapor flows are different. 


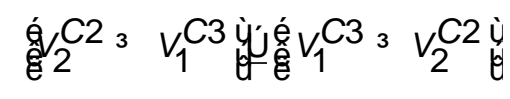

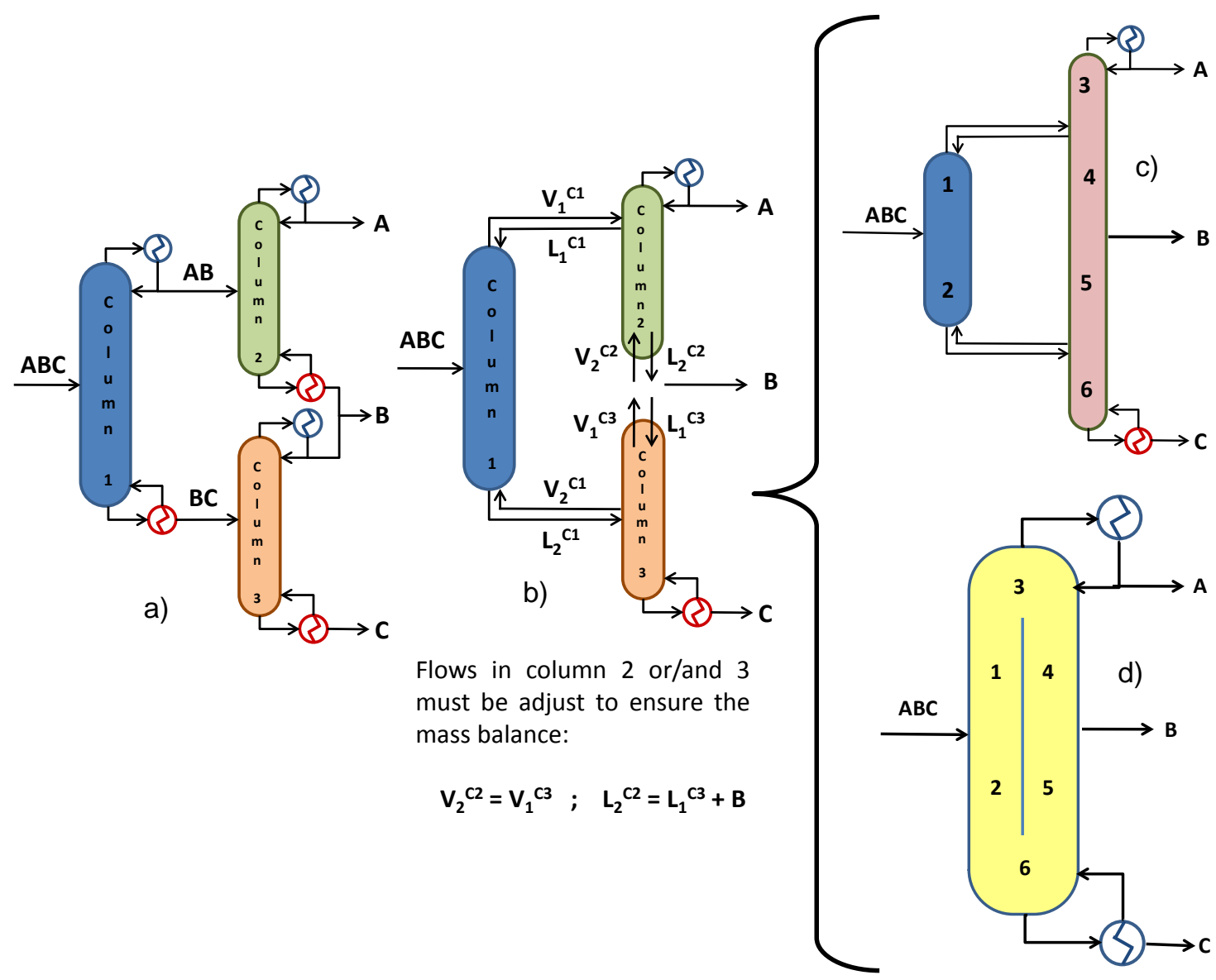

Figure 1. Generation by decomposition in basic tasks of Peltyuk configuration and Divided Wall Columns (DWC)

In this situation, there are different alternatives to solve this problem One of them is that the column with lower flows should adjust to the column with larger internal flows, For example if $v_{2}^{C 2}{ }^{3} \quad v_{1}^{C 3}$, the $v_{1}^{C 3}$ must be increased in $D V=v_{2}^{C 2}-v_{1}^{C 3}$ to make both flows even which increased the diameter of the column section and as a result the capital cost of column. Furthermore, the adjustment of flows produces that some sections work in suboptimal conditions (at least when compared to the individual separations tasks). This behavior is equivalent to say that the column with larger flows is the "dominant column". If the dominant column is column 3 we have to increase flows in column 2 and then condenser duty increases. If the dominant column is column 2 the flow adjustment in column 3 produces an increase in the reboiler duty.

Another alternative is Include an intermediate reboiler to provide the extra vapor needed in column C2. This alternative reduces the energetic cost because heat is supplied at a lower temperature than the reboiler. The third alternative is extracted the excess liquid/vapor stream 
and consider it as a cold/hot stream that can be used elsewhere in the plant and returning this stream as vapor/liquid to the column, which provide the excess needed in column 2.

The basic idea presented in the present study is to extract this excess vapor or liquid stream and used it in a VRC to reduce the energetic requirements of the column.

\section{Methodology}

As has been mentioned, the simulation of a DWC or its equivalent Petlyuk configuration can be carried out by decomposing in their three separation tasks (each one of these tasks can be simulated as a conventional distillation column) (Figure 1) .

The simulation in a commercial simulator is performed sequentially and consists of three stages. First of all, each one of the column should be characterized. To do that, we calculated the number of trays and the feed tray required in each column for a desired separation. To do this, we use a shortcut model: either Underwood-Fenske for near ideal systems; or simple trial and error for non-ideal systems. Note that we are not interested in optimizing the column, but only in developing an easy and reliable simulation.

Next, we simulated the Petlyuk configuration as combination of the three conventional columns. The connection between columns is done by thermal couplings. However, simulation of thermally coupled systems involving more than two columns (and in some cases even with two columns) is difficult, because the two side flows connecting the columns produce systems with a large number of 'recycle' streams (in a modular simulator these recycles are converged through tear streams). Whatever the method used to converge the flowsheet (e.g. fixed point, Newton or quasi-Newton methods), good initial values approximating the final solution are mandatory to converge the system, while maintaining product specifications. The presence of a large number of tear streams slows down the simulation, making convergence difficult. To solve this problem, Carlberg and Westerberg (Carlberg and Westerberg 1989; Carlberg and Westerberg 1989) proved, in the context of Underwood's shortcut method, that in a TCD system, the two side streams connecting the rectifying section of column 1 (see Figure 2) with column 2 are equivalent to a superheated vapor stream, whose flow is the net flow (i.e. the difference between vapor exiting the column and liquid entering the column). For the two side streams connecting the stripping section of column 1 (see Figure 2) with column 3 are equivalent to a subcooled liquid stream, whose flow is the net flow (i.e. the difference between liquid exiting the column and vapor entering the column). 


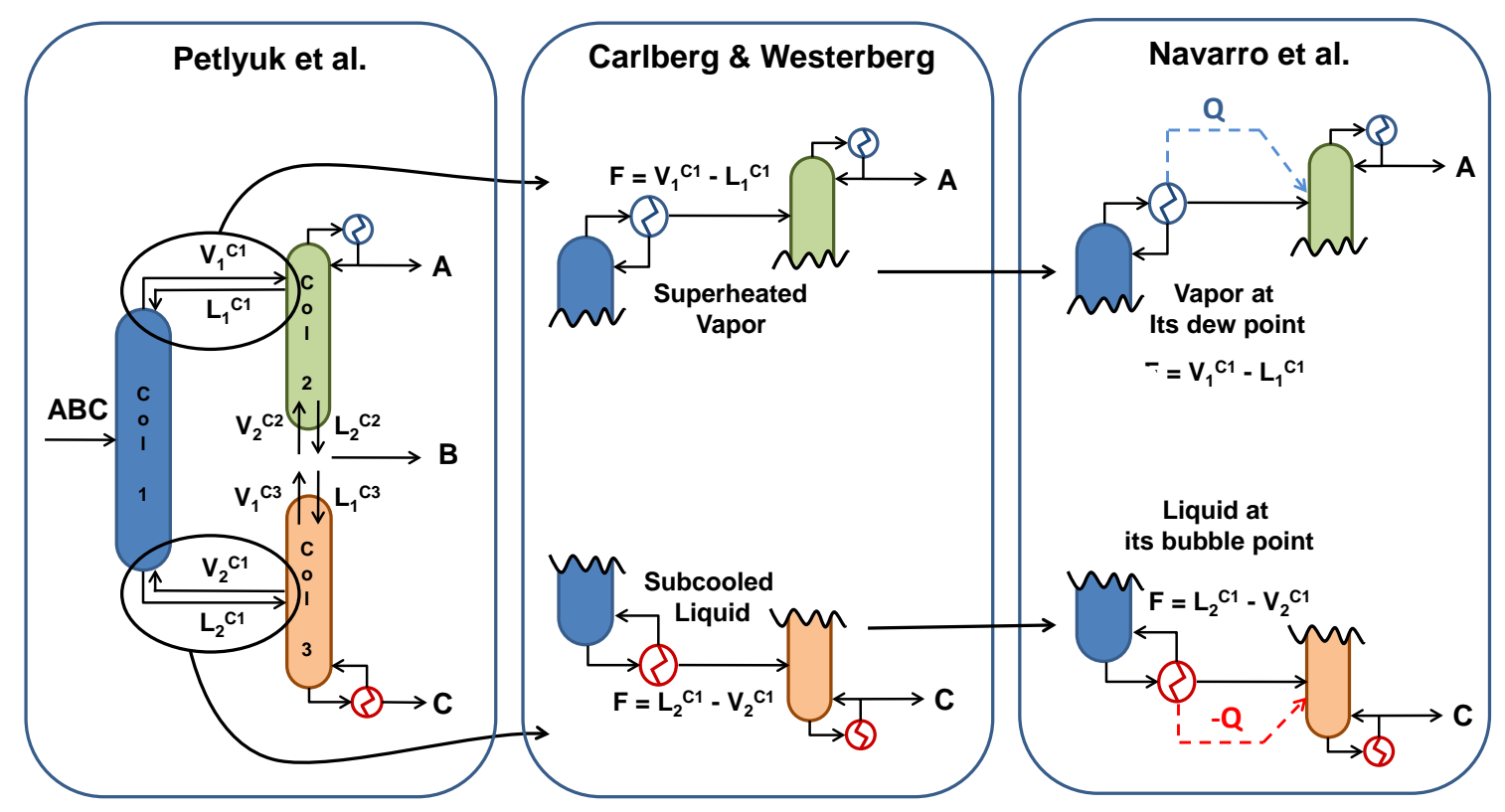

Figure 2. Equivalent configurations for a thermal coupling

However, in general, this approach cannot be implemented in modular process simulators, because the degree of superheating and/or subcooling can be so large that it might produce results without physical meaning, and thus the simulator may fail to converge. Navarro et al (Navarro et al. 2012) solved this problem. They check that it possible substitute the superheating or subcooling streams with a combination of a material stream and an energy stream, with average error $2 \%$ for 3 component mixture. In the rectifying section, the material stream is vapor at its dew point and the energy stream is equivalent to the energy removed if we include a partial condenser to provide reflux to the first column (see Figure 2). In the stripping section, the material stream is liquid at its bubble point, and the energy stream is equivalent to the energy added if we include a reboiler to provide vapor to the first column (see Figure 2).

Once it has been completed the Petlyuk configuration, the next and final step is the introduction of VRC. As discussed earlier, the objective is the use of excess vapor or liquid stream which is introduced from one to another section in column 2 of Petlyuk configuration. Depending on whether the stream in excess is vapor in stripping or liquid in enrichment section of the column, the cycle configuration is different, and consequently recovery heat or cold. The different configurations are discussed below. 


\section{- Excess of vapor stream in stripping section}

When the stream in excess is vapor in stripping section, the energy recovered will be obtained in form of heat, and it could be used in any part of the plant. In this case, this recovered energy will be used to reduce de energy utilities in the reboiler.

The VRC to heat recovery is as follows:

- The stream in excess is vapor at its dew point. This is extracted as a side stream in the column. First, it should be superheated to ensure it does not partially condenser in the subsequent compression stage

- Once heated to the required temperature, the stream must be compressed until its temperature reaches a value high enough to ensure a correct heat exchange with the stream to be heated. In this case, we considered that a temperature difference about $15^{\circ}$ ensure a correct heat exchange

- Next, this compressed stream must be introduced into a heat exchanger where its latent heat of condensation is used to vaporize part of the inlet liquid stream in the reboiler of the DWC, reducing the energetic cost here

- Then, the liquid steam is introduced into an expansion valve, where the pressure is reduced until this recovers the value of the operation pressure in DWC

- Due to the pressure loss, the liquid stream is partially vaporized. Therefore, this stream must be condensed prior to be introduced into the column. In this case, we used a heat exchanger to condenser it, using water as cooling fluid.

- Finally, this liquid stream (with same pressure inside the column) is divided into two streams. On the one hand, a part of this stream will be reintroduced to the column by the same floor where it was removed (providing the necessary extra reflux for the correct behavior of the stripping section of the column). And in the other hand, the second part of the stream is obtained as intermediate product

The scheme of VRC presented for heat recovery is shown in Figure 3.

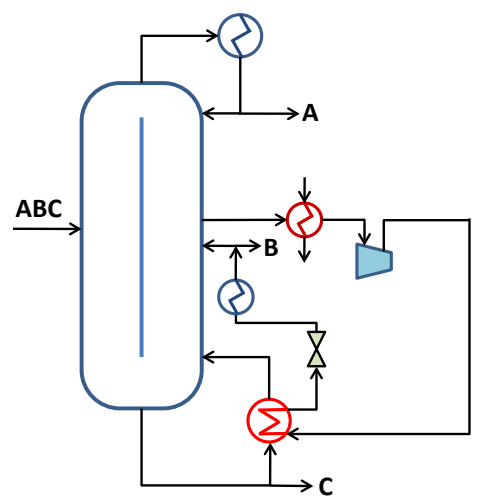

Figure 3. Scheme of VRC to heat recovery 


\section{- Excess of liquid stream in enrichment section}

When the stream in excess is liquid in enrichment section, the energy recovered will be obtained in form of cold, and it could be used in any part of the plant. In this case, this recovered energy will be used to reduce de energy utilities in the condenser. Note that this configuration only presents significant economic savings when the cooling utilities temperatures are below $0^{\circ} \mathrm{C}$. Because in these cases, the refrigeration cost is very expensive.

The VRC to cold recovery is as follows:

- The stream in excess is liquid at its bubble point. This is extracted as a side stream in the column. The aim is to decrease the temperature of this stream to be used as cooling utility in the condenser. To do this, the stream pressure is reduced until its temperature reaches a value low enough to ensure a correct heat exchange with the stream to be cooled. In this case, we considered that a temperature difference about $15^{\circ}$ ensure a correct heat exchange Due to the pressure loss, the liquid stream is partially vaporized.

- Next, this stream must be introduced into a heat exchanger where its latent heat of evaporation is used to condense part of the inlet liquid stream in the condenser of the DWC, reducing the energetic cost here

- Once this stream totally vaporized, the vapor steam is introduced into an compressor, where the pressure is increased until this recovers the value of the operation pressure in DWC. In this case, because the compressor efficiency is less than $100 \%$, an overheating occurs in the outlet compression stream, this ensure a vapor stream in the compressor output

- Finally, this vapor stream (with same pressure inside the column) will be reintroduced to the column by the same floor where it was removed (providing the necessary extra reflux for the correct behavior of the enrichment section of the column)

The scheme of VRC presented for heat recovery is shown in Figure 4.

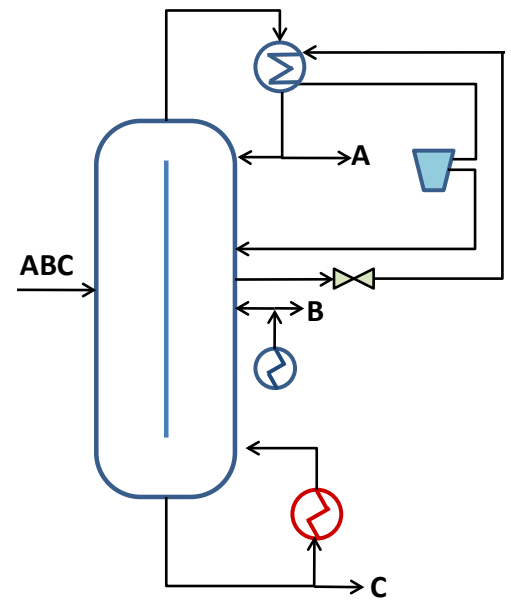

Figure 4. Scheme of VRC to heat recovery 


\section{Examples and Results}

In this section, different examples are presented. Corresponding to each one of the options presented, one case which heat is recovered (see Figure 3) and another case which cold is recovered (see Figure 4). It should be noted that the installation of the recompression cycles involves the use of quite expensive equipment, such as compressors. It may be the case that the energy savings achieved is not compensated with the new equipment cost. Therefore it is necessary to estimate and quantify the additional cost that takes place in the wake of the purchase and installation of equipment consisting recompression cycle. The calculation of the equipment cost has been done by using correlations. In the literature, there are numerous different correlations for the calculation of equipment cost, but in this paper we have chosen to use the correlations provided by Turton et al. (Turton et al. 2008). Finally, the prices obtained must be updated to 2012, using the "Plant Cost Index chemical engineering" (CEPCI). The annual cost of different equipment is calculated assuming 10 years as operation time and an interest rate per year at $8 \%$ (Smith 2005). All simulations were performed using ASPEN-HYSYS using SRK equation of state and default values. The characteristic of different utilities (both hot and cold) used are shown in Table 1

Table 1. Characteristics of hot/cold utilities

\begin{tabular}{lccc}
\multicolumn{1}{c}{ Utilities } & $\mathbf{T}_{\text {in }}(\mathbf{\circ} \mathbf{C})$ & $\mathbf{T}_{\text {out }}(\mathbf{\circ} \mathbf{C})$ & Cost (\$/GJ)* \\
\hline Steam & & & \\
$\quad$ Atm Pressure (1 bar) & 100 & 100 & 6,67 \\
$\quad$ Low Pressure (6 bar) & 160 & 160 & 7,78 \\
$\quad$ Medium Pressure (11 bar) & 184 & 184 & 8,22 \\
$\quad$ High Pressure (42 bar) & 254 & 254 & 9,83 \\
& & & \\
\hline Water & 20 & 40 & 0,354 \\
\hline Refrigeration & & & \\
$\quad$ Low Temperature & -20 & -20 & 7,89 \\
$\quad$ Very Low Temperature & -50 & -50 & 13,11 \\
\hline
\end{tabular}

* All prizes are referred to 2002 


\subsection{Heat recovery configuration (excess of vapor stream in stripping section)}

The first one consists in the separation of the mixture of aromatics ( $p$-xylene, cumene, 1,2,4-trimethylbenzene).

The methodology used to do the simulation of the separation of this system using Petlyuk/DWC was discussed in detail in chapter 3. The main characteristics of the different streams involved in the studied simulation are shown in Table 2.

Table 2. Characteristics of different streams in the separation system

\begin{tabular}{lcccccc}
\hline & \multirow{2}{*}{$\mathbf{P}(\mathbf{a t m})$} & $\mathbf{T}\left({ }^{\circ} \mathbf{C}\right)$ & \multirow{2}{*}{$\begin{array}{c}\text { Molar Flow } \\
(\mathbf{k m o l} / \mathbf{h})\end{array}$} & $\mathbf{p}$-xylene & cumene & $\mathbf{1 , 2 , 4 - t r i m e t h y l b e n z e n e ~}$ \\
\hline Feed ABC & 1,00 & 153,7 & 200,00 & 0,3000 & 0,3000 & 0,4000 \\
Product A & 1,00 & 139,1 & 60,00 & $\mathbf{0 , 9 9 9 8}$ & 0,0002 & 0,0000 \\
Product B & 1,00 & 153,7 & 60,03 & 0,0010 & $\mathbf{0 , 9 9 7 7}$ & 0,0013 \\
Product C & 1,00 & 169,4 & 79,97 & 0,0000 & 0,0006 & $\mathbf{0 , 9 9 9 4}$ \\
\hline
\end{tabular}

Once, each one of the columns has been characterized using a shortcut model. The first step is to simulate and calculate the energy consumption and cost associated with the separation using a conventional Petlyuk column. The scheme of the Petlyuk column simulated is shown in Figure 5.

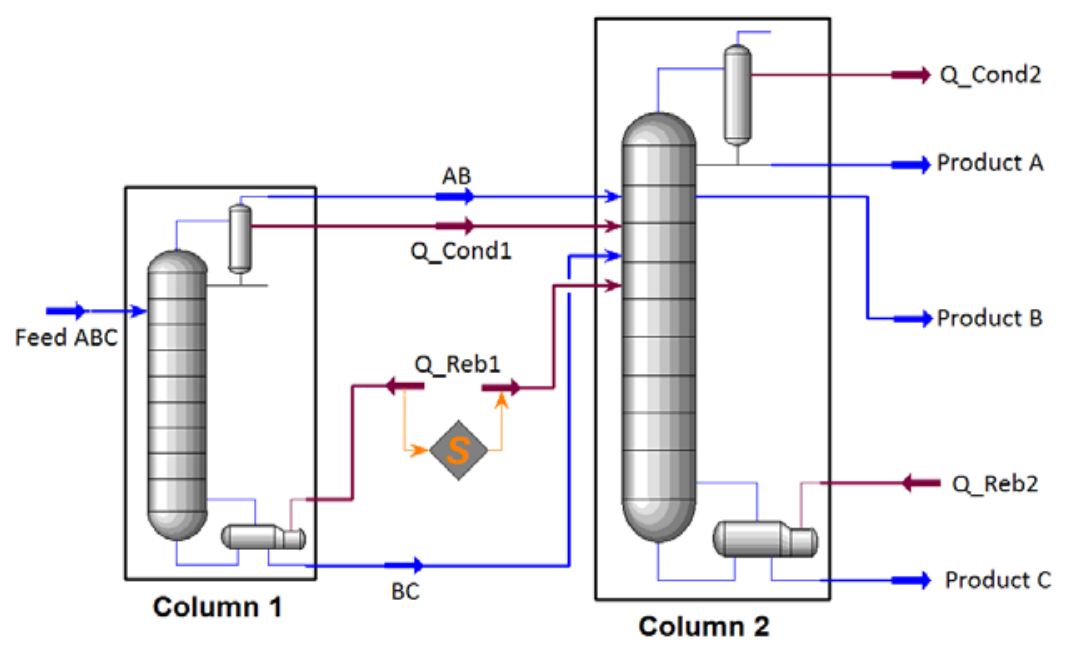

Figure 5. Simulation of Petlyuk configuration column

The next step is to study the effect of introducing the VRC in previous Petlyuk column. To do this, we simulate and calculate the energy consumption and cost associated with this system. The scheme of this configuration is shown in Figure 6. 
The results obtained in both systems are shown in Tables 3 and 4.

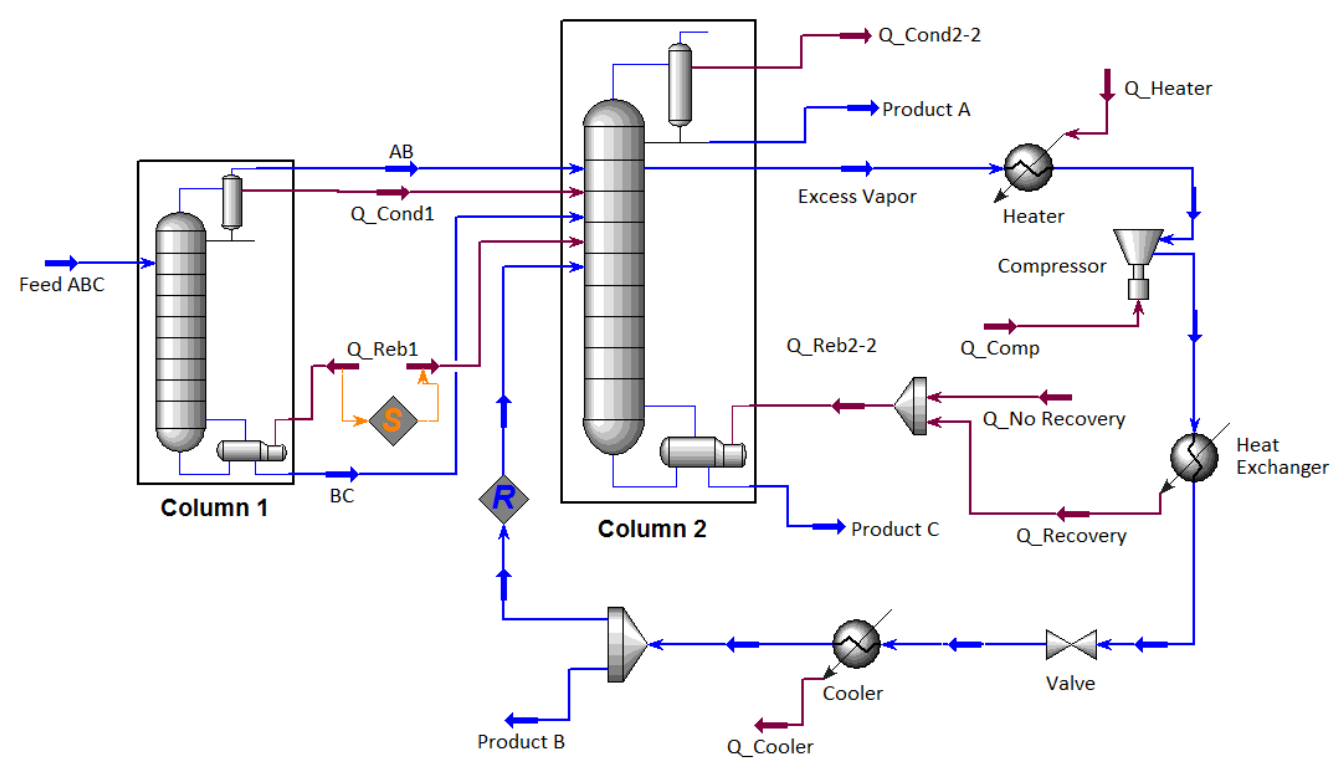

Figure 6. Simulation of Petlyuk configuration column with VRC

Table 3. Conventional Petlyuk Distillation column: Capital \& Energy Cost

\begin{tabular}{|c|c|c|c|c|c|c|}
\hline \multicolumn{7}{|c|}{ EQUIPMENTS } \\
\hline \multicolumn{3}{|c|}{ COLUMNS } & \multicolumn{2}{|c|}{ CONDENSER } & \multicolumn{2}{|c|}{ REBOILER } \\
\hline & Column 1 & Column 2 & & & & \\
\hline$V(m 3)$ & 95,2 & 316,7 & $A(m 2)$ & 222,1 & $A(m 2)$ & 1273,1 \\
\hline Cost $(€)$ & 359994 & 981392 & Cost $(€)$ & 128751 & Cost $(€)$ & 359280 \\
\hline $\begin{array}{l}\text { Anual cost } \\
\text { (€/year) }\end{array}$ & 53650 & 146256 & $\begin{array}{l}\text { Anual cost } \\
\text { (€/year) }\end{array}$ & 19188 & $\begin{array}{l}\text { Anual cost } \\
\text { (€/year) }\end{array}$ & 53543 \\
\hline \multicolumn{3}{|c|}{ TOTAL ANNUAL COST } & \multicolumn{4}{|c|}{ ENERGY } \\
\hline & & & CONDE & SER & REB & LER \\
\hline Equipment & \multicolumn{2}{|c|}{272637} & Energy (kw) & 8772 & Energy $(\mathrm{kw})$ & 8826 \\
\hline Energy & \multicolumn{2}{|c|}{2175186} & Cold Utility & Water & Hot Utility & MP Steam \\
\hline Total Cost & \multicolumn{2}{|c|}{2447823} & $\begin{array}{l}\text { Energy Cost } \\
\text { (€/year) }\end{array}$ & 89284 & $\begin{array}{l}\text { Energy Cost } \\
\text { (€/year) }\end{array}$ & 2085902 \\
\hline
\end{tabular}


Table 4. Conventional Petlyuk Distillation with VRC: Capital \& Energy Cost

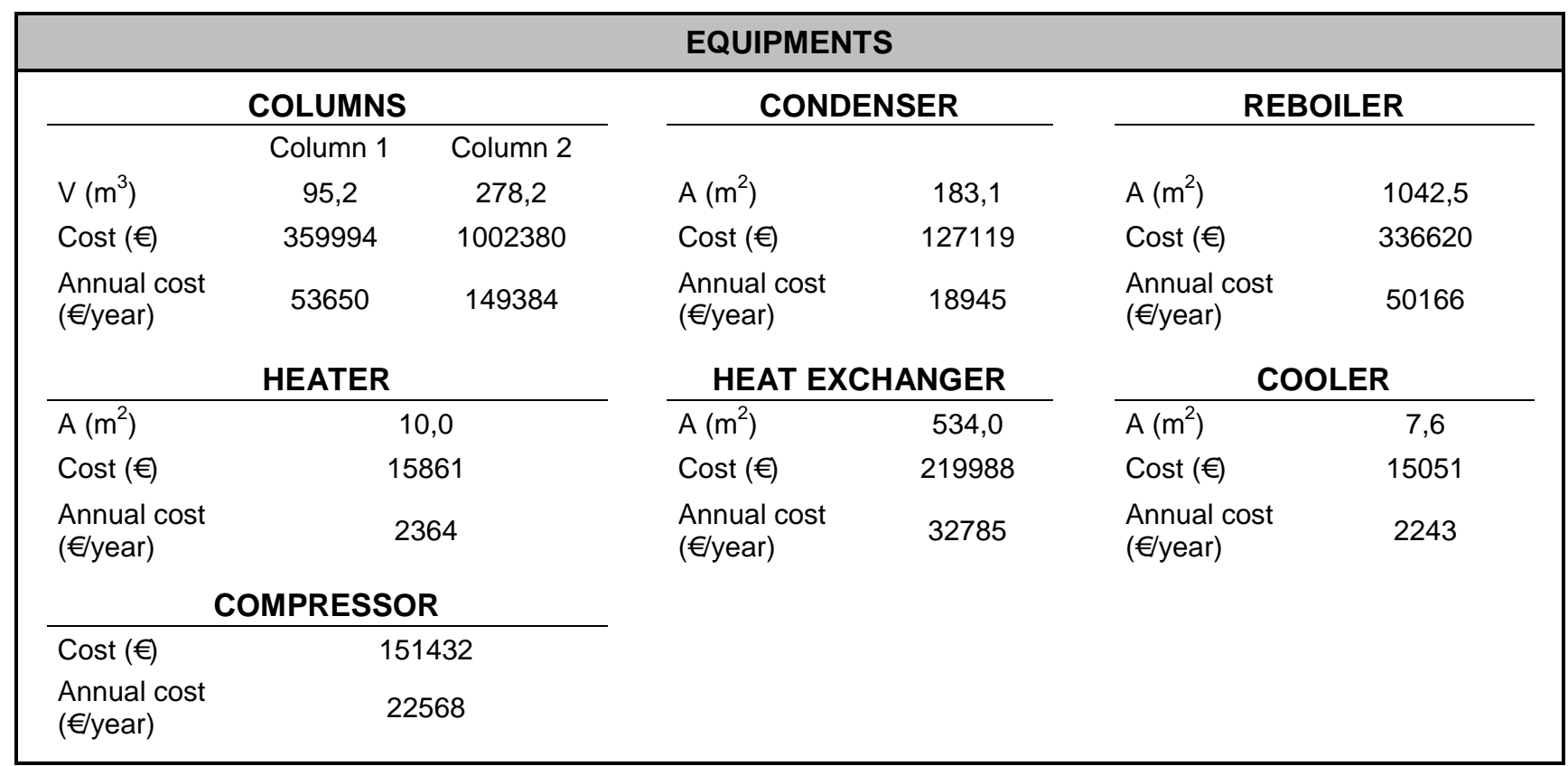

\begin{tabular}{|c|c|c|c|c|c|}
\hline \multicolumn{6}{|c|}{ ENERGY } \\
\hline \multicolumn{2}{|c|}{ COMPRESSOR } & \multicolumn{2}{|c|}{ CONDENSER } & \multicolumn{2}{|c|}{ REBOILER } \\
\hline Energy (kw) & 145 & Energy (kw) & 7231 & Energy (kw) & 7227 \\
\hline Utility & Electricity & Cold Utility & Water & Hot Utility & MP Steam \\
\hline $\begin{array}{l}\text { Energy Cost } \\
\text { (€/year) }\end{array}$ & 69368 & $\begin{array}{l}\text { Energy Cost } \\
\text { (€/year) }\end{array}$ & 73595 & $\begin{array}{l}\text { Energy Cost } \\
\text { (€/year) }\end{array}$ & 1708072 \\
\hline \multicolumn{2}{|c|}{ TOTAL ANNUAL COST } & \multicolumn{2}{|c|}{ COOLER } & \multicolumn{2}{|c|}{ HEATER } \\
\hline & & Energy (kw) & 338 & Energy (kw) & 299 \\
\hline Equipment & 332104 & Cold Utility & Water & Cold Utility & HP Steam \\
\hline Energy & 1938855 & \multirow[t]{2}{*}{$\begin{array}{l}\text { Energy Cost } \\
\text { (€/year) }\end{array}$} & \multirow[t]{2}{*}{3441} & \multirow[t]{2}{*}{$\begin{array}{l}\text { Energy Cost } \\
\text { (€/year) }\end{array}$} & 84378 \\
\hline Total Cost & 2270959 & & & & \\
\hline
\end{tabular}

The results lead to important conclusions. First, and as expected, the introduction of the CRV in the conventional Petlyuk column generates significant energy savings. It is interesting remark that the savings in energy in the reboiler are greater than $18 \%$. There is also a similar reduction in the energy consumption in the condenser. As expected, the installation of the VRC increases capital cost, particularly the investment increases by $22 \%$, but the global energy cost reduces by $11 \%$. The investment is amortized in less of three years of operation. After the amortization the savings in utilities cost is around $180000 € /$ year.

But there are more configurations of distillation columns to separate this mixture, as direct or indirect distillation. Furthermore, it is possible to use VRC in any of these configurations (for this mixture, the VRC is only recommended for direct distillation). To check that the 
configuration proposed in this work provided the best results, we studied the same separation using the other configurations. The schemes of other configurations are shown in Figure 7.

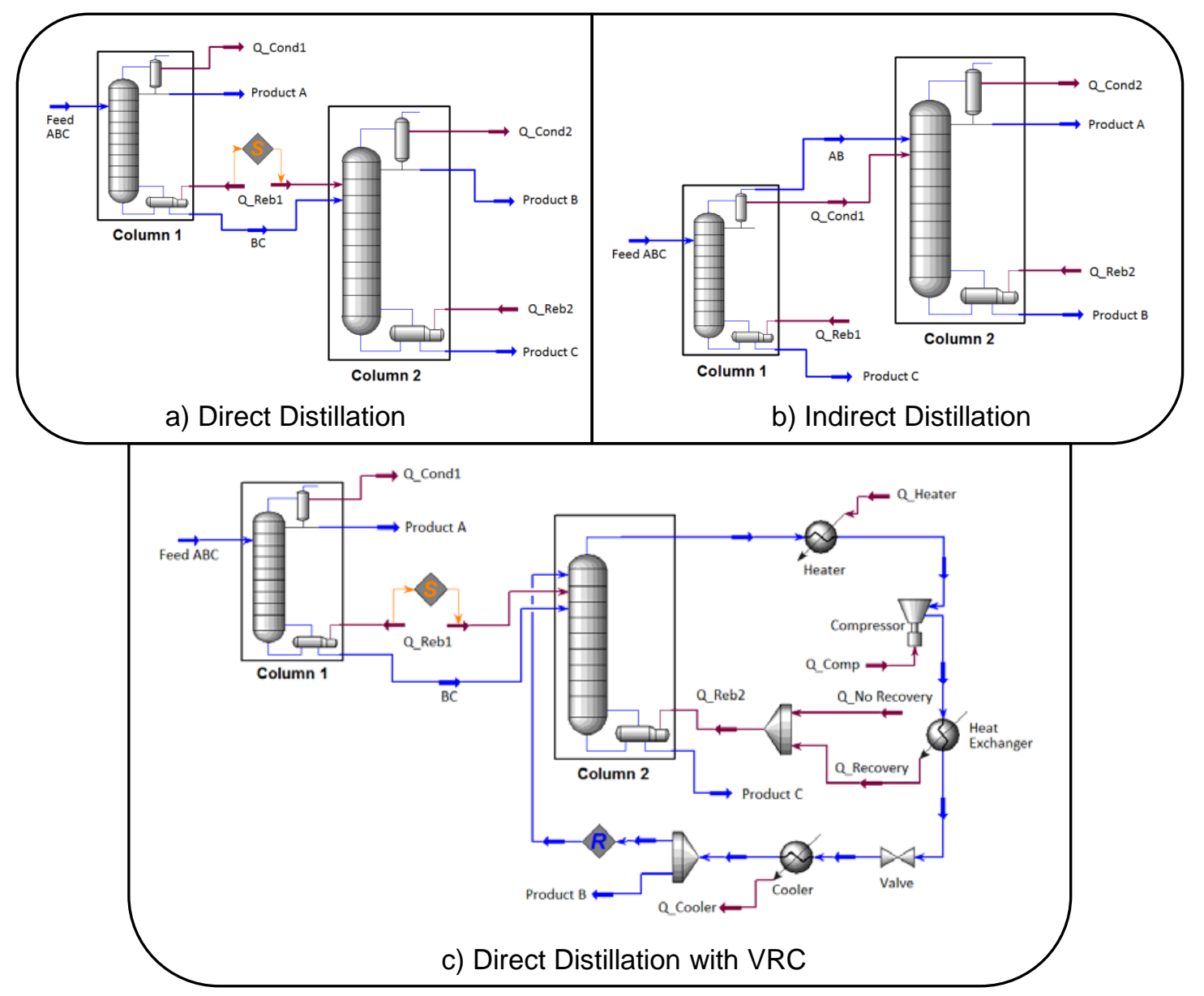

Figure 7. Scheme of direct distillation with \& without VRC and indirect distillation

The results obtained in each configuration in detail are shown in Appendix A. To check which best configuration is, we have compared the cost associated to each one. The results are shown in Figure 8.

The results show that the configuration with the lowest total annual cost is Petlyuk Distillation with VRC. It is interesting remark that the savings in energy outweigh the additional cost associated with the purchase and installation of VRC in both Petlyuk and direct distillation. Although as can be seen, lower energy costs are achieved with the configuration proposed in this paper. 


\section{Total Costs in each configuration}

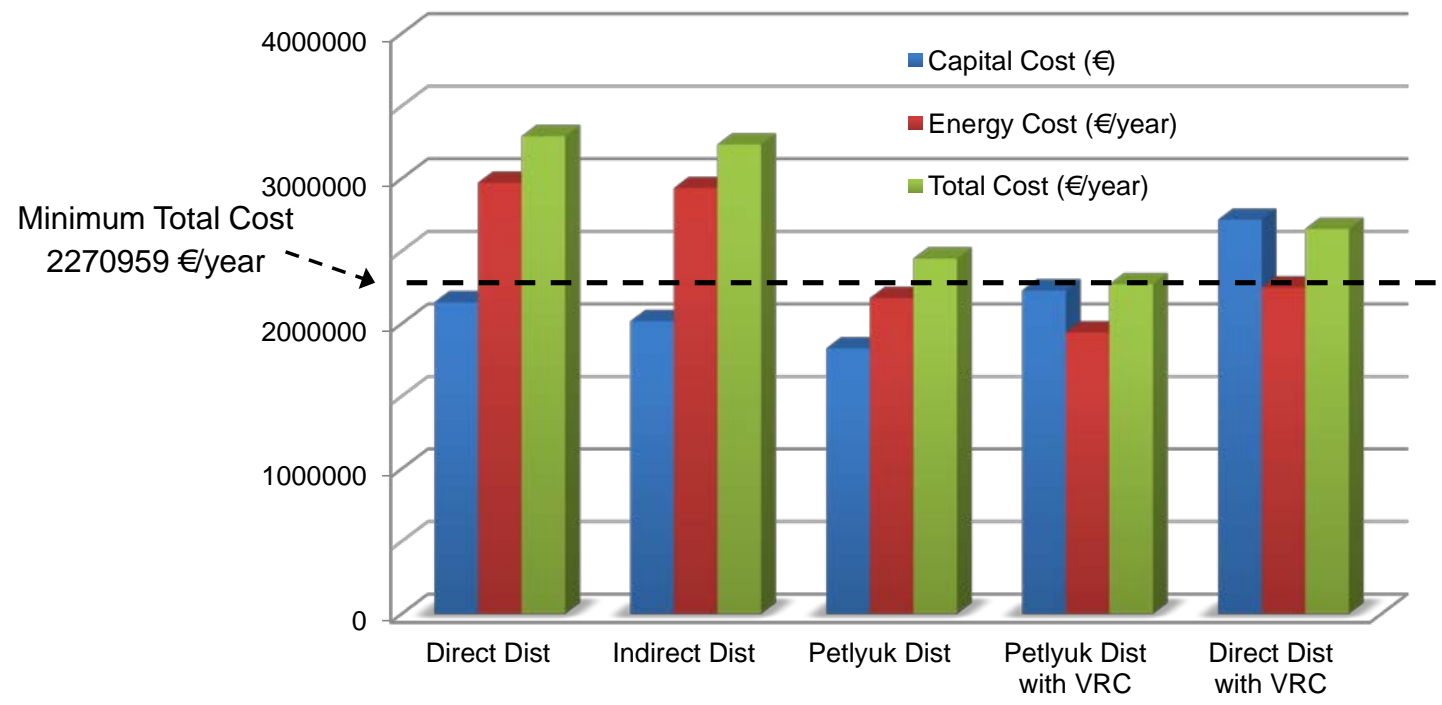

Figure 8. Costs in all possible distillation systems

\subsection{Cold recovery configuration (excess of vapor stream in enrichment section)}

The first one consists in the separation of the mixture of hydrocarbons (ethylene, ethane, propane).

The methodology used to do the simulation of the separation of this system using Petlyuk/DWC was discussed in detail in chapter 3. The main characteristics of the different streams involved in the studied simulation are shown in Table 5.

Table 5. Characteristics of different streams in the separation system

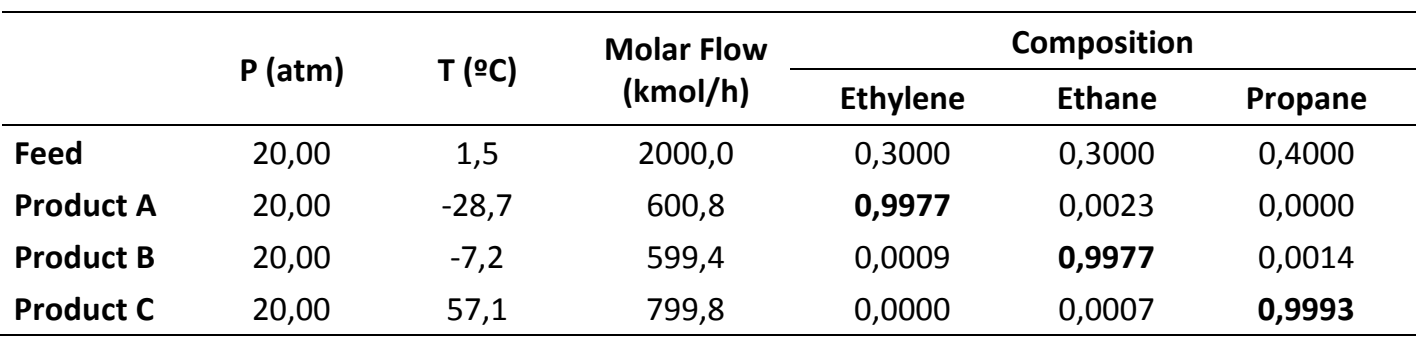

Once, each one of the columns has been characterized using a shortcut model. The first step is to simulate and calculate the energy consumption and cost associated with the separation using a conventional Petlyuk column. The scheme of the Petlyuk column simulated is similar that shown in Figure 5.

The next step is to study the effect of introducing the VRC in previous Petlyuk column. To do this, we simulate and calculate the energy consumption and cost associated with this system. The scheme of this configuration is shown in Figure 9. 


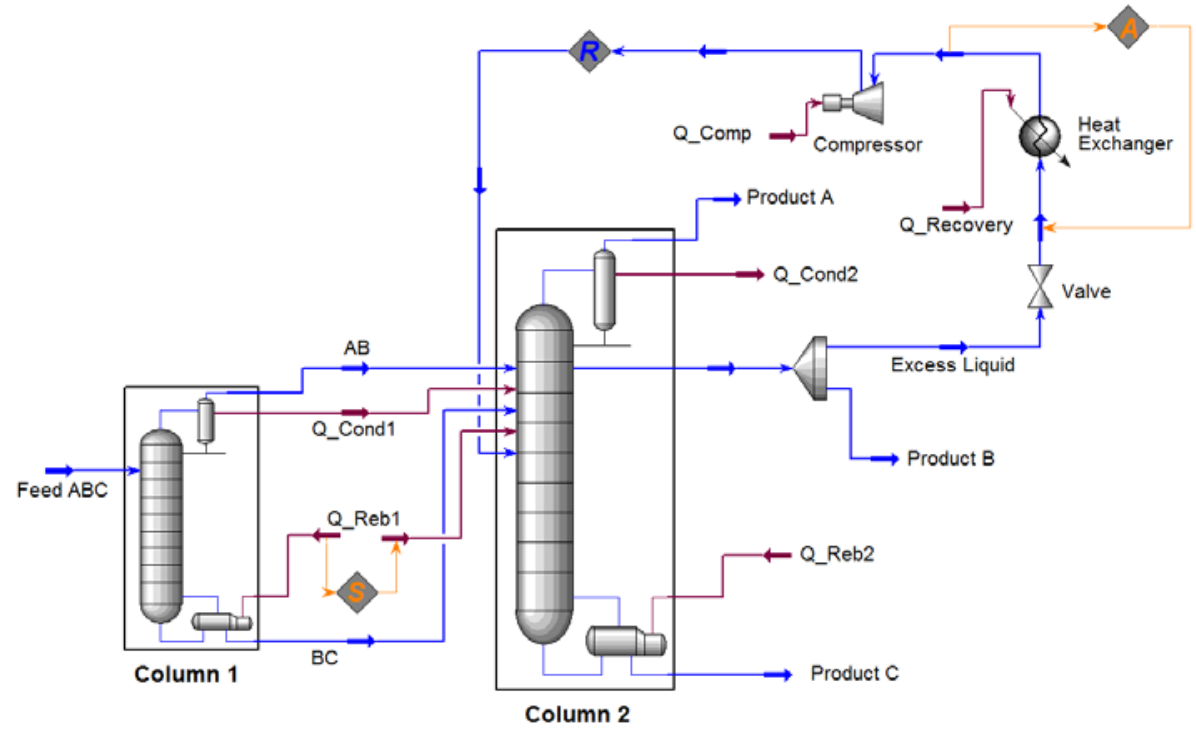

Figure 9. Simulation of Petlyuk configuration column with VRC

The results obtained in both systems are shown in Tables 6 and 7 .

Table 6. Conventional Petlyuk Distillation column: Capital \& Energy Cost

\begin{tabular}{|c|c|c|c|c|c|c|}
\hline \multicolumn{7}{|c|}{ EQUIPMENTS } \\
\hline \multicolumn{3}{|c|}{ COLUMNS } & \multicolumn{2}{|c|}{ CONDENSER } & \multicolumn{2}{|c|}{ REBOILER } \\
\hline & Column 1 & Column 2 & & & & \\
\hline$V\left(m^{3}\right)$ & 49,6 & 287,4 & $A\left(m^{2}\right)$ & 1804,0 & $A\left(m^{2}\right)$ & 817,1 \\
\hline Cost $(€)$ & 521794 & 2941774 & Cost $(€)$ & 471174 & $\operatorname{Cost}(€)$ & 269591 \\
\hline $\begin{array}{l}\text { Anual cost } \\
\text { (€/year) }\end{array}$ & 77763 & 438411 & $\begin{array}{l}\text { Anual cost } \\
\text { (€/year) }\end{array}$ & 70219 & $\begin{array}{l}\text { Anual cost } \\
\text { (€/year) }\end{array}$ & 40177 \\
\hline
\end{tabular}

\begin{tabular}{|lc|}
\hline \multicolumn{2}{|c|}{ TOTAL ANUAL COST } \\
\hline Equipment & 626570 \\
Energy & 8430906 \\
\hline Total Cost & 9057476 \\
\hline
\end{tabular}

\begin{tabular}{|c|c|c|c|}
\hline \multicolumn{4}{|c|}{ ENERGY } \\
\hline \multicolumn{2}{|c|}{ CONDENSER } & \multicolumn{2}{|c|}{ REBOILER } \\
\hline Energy (kw) & 13940,5 & Energy (kw) & 16561,6 \\
\hline Cold Utility & $\begin{array}{l}\text { Very Low Temp } \\
\text { Refrigerant }\end{array}$ & Hot Utility & $\begin{array}{c}\text { Atm Pressure } \\
\text { Steam }\end{array}$ \\
\hline $\begin{array}{l}\text { Energy Cost } \\
\text { (€/year) }\end{array}$ & 5254756 & $\begin{array}{l}\text { Energy Cost } \\
\text { (€/year) }\end{array}$ & 3176150 \\
\hline
\end{tabular}


Table 7. Conventional Petlyuk Distillation with VRC: Capital \& Energy Cost

\begin{tabular}{|c|c|c|c|c|c|c|}
\hline \multicolumn{7}{|c|}{ EQUIPMENTS } \\
\hline \multicolumn{3}{|c|}{ COLUMNS } & \multicolumn{2}{|c|}{ CONDENSER } & \multicolumn{2}{|c|}{ REBOILER } \\
\hline & Column 1 & Column 2 & & & & \\
\hline$V\left(m^{3}\right)$ & 49,6 & 257,7 & $A\left(m^{2}\right)$ & 1168,5 & $A\left(m^{2}\right)$ & 512,7 \\
\hline Cost $(€)$ & 521794 & 2354008 & Cost $(€)$ & 343114 & Cost $(€)$ & 202340 \\
\hline $\begin{array}{l}\text { Anual cost } \\
\text { (€/year) }\end{array}$ & 77763 & 350817 & $\begin{array}{l}\text { Anual cost } \\
\text { (€/year) }\end{array}$ & 51134 & $\begin{array}{l}\text { Anual cost } \\
\text { (€/year) }\end{array}$ & 30155 \\
\hline \multicolumn{3}{|c|}{ COMPRESSOR } & \multicolumn{2}{|c|}{ HEAT EXCHANGER } & & \\
\hline & & & $A\left(m^{2}\right)$ & 6844,1 & & \\
\hline Cost $(€)$ & \multicolumn{2}{|c|}{946032} & Cost $(€)$ & 1474823 & & \\
\hline $\begin{array}{l}\text { Anual cost } \\
\text { ( } € / \text { year) }\end{array}$ & \multicolumn{2}{|c|}{140987} & $\begin{array}{l}\text { Anual cost } \\
\text { (€/year) }\end{array}$ & 219792 & & \\
\hline
\end{tabular}

\begin{tabular}{|c|c|c|c|c|c|}
\hline \multicolumn{6}{|c|}{ ENERGY } \\
\hline \multicolumn{2}{|c|}{ COMPRESSOR } & \multicolumn{2}{|c|}{ CONDENSER } & \multicolumn{2}{|c|}{ REBOILER } \\
\hline Energy (kw) & 1365 & Energy (kw) & 9011 & Energy (kw) & 10422 \\
\hline Utility & Electricity & Cold Utility & $\begin{array}{l}\text { Very Low Temp } \\
\text { Refrigerant }\end{array}$ & Hot Utility & $\begin{array}{c}\text { Atm Pres } \\
\text { Steam }\end{array}$ \\
\hline $\begin{array}{l}\text { Energy Cost } \\
\text { (€/year) }\end{array}$ & 654055 & $\begin{array}{l}\text { Energy Cost } \\
\text { (€/year) }\end{array}$ & 3396472 & $\begin{array}{l}\text { Energy Cost } \\
\text { (€/year) }\end{array}$ & 1998676 \\
\hline
\end{tabular}

\section{TOTAL ANUAL COST}

\begin{tabular}{|lc|}
\hline Equipment & 870647 \\
Energy & 6049203 \\
\hline Total Cost & 6919850 \\
\hline
\end{tabular}

As previous example, the results lead to similar and important conclusions. First, the introduction of the CRV in the conventional Petlyuk column generates significant energy savings. It is interesting remark that the savings in energy in the reboiler are greater than $35 \%$. There is also a similar reduction in the energy consumption in the condenser. As expected, the installation of the VRC increases capital cost, particularly the investment increases by $38 \%$, but the global energy cost reduces by $28 \%$. The investment is amortized in the first year of operation. After the amortization the savings in utilities cost is around $2380000 € /$ year.

But there are more configurations of distillation columns to separate this mixture, as direct or indirect distillation. Furthermore, it is possible to use VRC in any of these configurations (for this mixture, the VRC is only recommended for indirect distillation). To check that the configuration proposed in this work provided the best results, we studied the same separation using the other configurations. The schemes of direct and indirect configurations are similar to the Figure $7 \mathrm{a}$ and $7 \mathrm{~b}$, the scheme of indirect distillation with VRC is shown in Figure 10. 


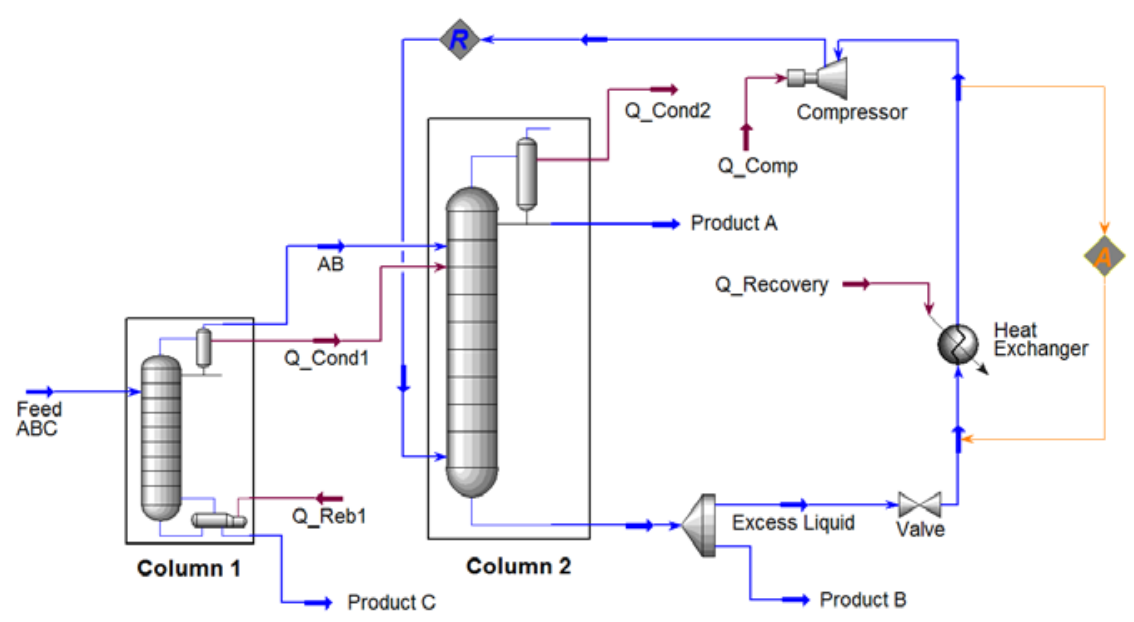

Figure 10. Simulation of indirect distillation column with VRC

The results obtained in each configuration in detail are shown in Appendix A. To check which best configuration is, we have compared the cost associated to each one. The results are shown in Figure 11.

The results show that the configuration with the lowest total annual cost is Petlyuk Distillation with VRC. It is interesting remark that the savings in energy outweigh the additional cost associated with the purchase and installation of VRC in both Petlyuk and indirect distillation. Although as can be seen, lower energy costs are achieved with the configuration proposed in this paper.

Total Cost in each configuration

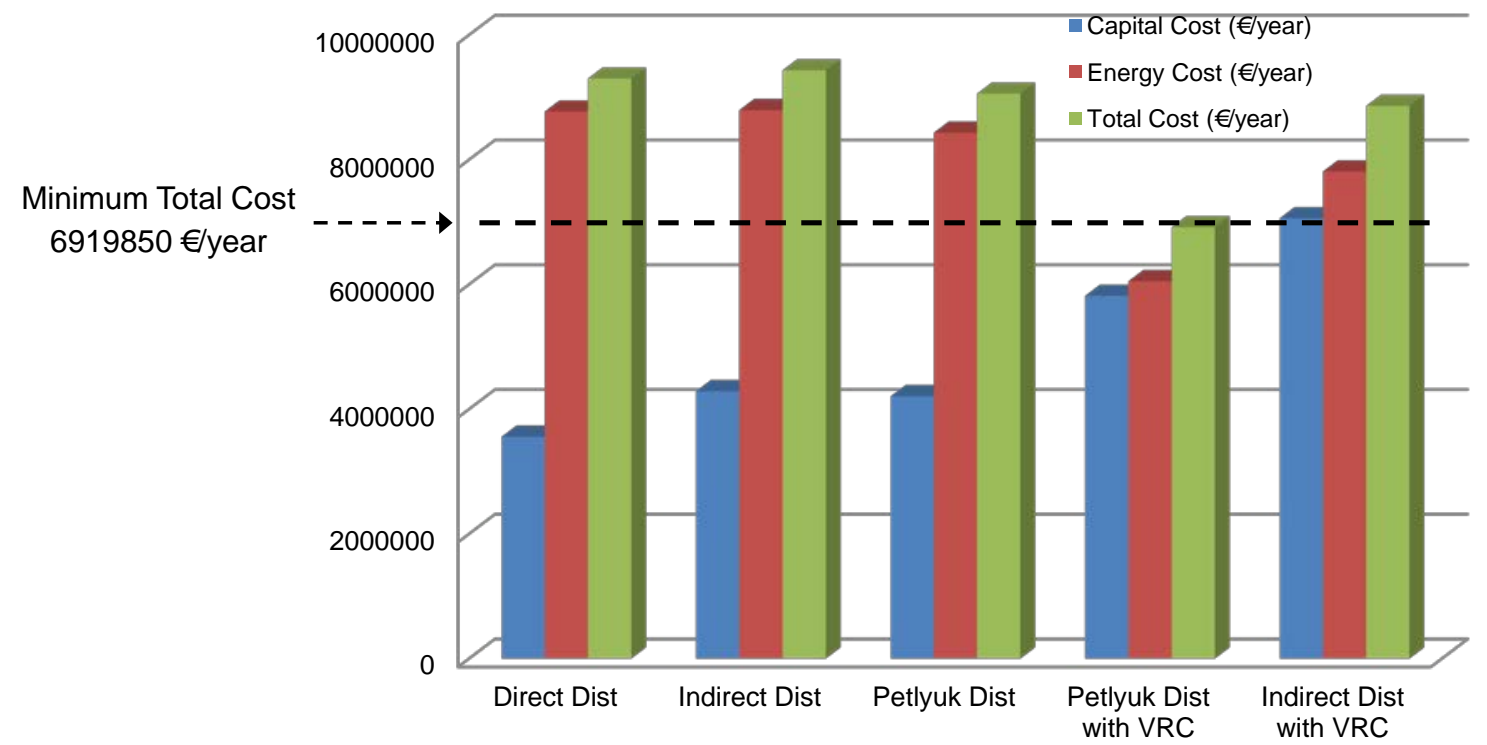

Figure 11. Costs in all possible distillation systems 


\section{Conclusions}

Some of the characteristics of these new arrangements are the following:

1. In Petlyuk/DWCs is usually not economically attractive to implement a vapor compression cycle between condenser and reboiler due to the large difference of temperatures (there is at least one component with an intermediate boiling point) and therefore large compression ratios. This implies that the installation of a VRC needs very large compressors or complex systems of compressors. That consumes high energy level and consequently the capital costs of these VRC are very expensive. But this problem is solved with this arrangement due to the difference of temperatures is smaller and then the alternative could be economically attractive.

2. Both the heat duties in reboiler and condenser are reduced: the first one is due to the heat integration in the vapor compression; the other due to the reduction of internal vapor and liquid flows in the corresponding section.

3. There is a tradeoff between the savings in energy consumption in reboilers and condensers and, the investment and operation of the new equipment, mainly the compressor.

In conclusion, the new arrangement presented is an important alternative to current methods for saving energy in the field of distillation. In general, this configuration is preferred in cases where one or several components of the mixture to be separated have volatilities far from the others. This causes that both vapor and liquid flow are very different between coupled sections in the Petlyuk column, achieving favorable conditions for the installation this type of cycles. As demonstrated, the economic savings obtained are very important, the order of 20 $40 \%$ of the initial cost, but there are extreme cases where the savings can be much larger. 


\section{Appendix A. Detailed results of all examples}

In next tables, the detailed results of all studied configuration (direct, indirect, Petlyuk distillation with and without VRC) are shown.

\section{A.1 Results of example 4.1 "Heat recovery configuration (excess of vapor stream} in stripping section)"

Table A.1. Annual Capital Cost in all studied configuration (€/year)

Direct Dist
Indirect Dist
Petlyuk Dist
Petlyuk Dist with VRC
Indirect Dist with VRC
Direct Dist
Indirect Dist
Petlyuk Dist
Petlyuk Dist with VRC
Indirect Dist with VRC

Direct Dist

Indirect Dist

Petlyuk Dist

Petlyuk Dist with VRC

Indirect Dist with VRC

Direct Dist

Indirect Dist

Petlyuk Dist

Petlyuk Dist with VRC

Indirect Dist with VRC

Direct Dist

Indirect Dist

Petlyuk Dist

Petlyuk Dist with VRC

Indirect Dist with VRC

\begin{tabular}{|c|c|c|c|c|c|}
\hline \multicolumn{6}{|c|}{ CAPITAL COST } \\
\hline \multicolumn{6}{|c|}{ COLUMNS } \\
\hline \multicolumn{3}{|c|}{ Column 1} & \multicolumn{3}{|c|}{ Column 2} \\
\hline$V\left(m^{3}\right)$ & Cost $(€)$ & $\begin{array}{c}\text { Annual cost } \\
\text { (€/year) }\end{array}$ & $V\left(m^{3}\right)$ & Cost $(€)$ & $\begin{array}{c}\text { Annual cost } \\
\text { (€/year) }\end{array}$ \\
\hline 201,6 & 728181 & 108520 & 205,0 & 754207 & 112399 \\
\hline 189,7 & 687087 & 102396 & 192,6 & 706815 & 105336 \\
\hline 95,2 & 360010 & 53652 & 316,7 & 1136213 & 169329 \\
\hline 95,2 & 360010 & 53652 & 278,2 & 1002326 & 149376 \\
\hline 201,6 & 728181 & 108520 & 192,6 & 706815 & 105336 \\
\hline \multicolumn{3}{|c|}{ CONDENSER (Column 1) } & \multicolumn{3}{|c|}{ REBOILER (Column 1) } \\
\hline$A\left(m^{2}\right)$ & Cost $(€)$ & $\begin{array}{c}\text { Annual cost } \\
\text { (€/year) }\end{array}$ & $A\left(m^{2}\right)$ & Cost $(€)$ & $\begin{array}{c}\text { Annual cost } \\
\text { (€/year) }\end{array}$ \\
\hline 189,0 & 119893 & 17868 & - & - & - \\
\hline- & - & - & 1109,4 & 326202 & 48614 \\
\hline- & - & - & - & - & - \\
\hline- & - & - & - & - & - \\
\hline- & - & - & 189,0 & 119694 & 17838 \\
\hline \multicolumn{3}{|c|}{ CONDENSER (Column 2) } & \multicolumn{3}{|c|}{ REBOILER (Column 2) } \\
\hline$A\left(m^{2}\right)$ & Cost $(€)$ & $\begin{array}{c}\text { Annual cost } \\
\text { (€/year) }\end{array}$ & $A\left(m^{2}\right)$ & Cost $(€)$ & $\begin{array}{c}\text { Annual cost } \\
\text { (€/year) }\end{array}$ \\
\hline 101,4 & 93491 & 13933 & 1738,5 & 451580 & 67299 \\
\hline 300,8 & 149166 & 22230 & 293,3 & 147277 & 21949 \\
\hline 222,1 & 128757 & 19189 & 1273,1 & 359296 & 53546 \\
\hline 183,1 & 127125 & 18945 & 1042,5 & 336634 & 50168 \\
\hline 1047,3 & 313532 & 46726 & - & - & - \\
\hline \multicolumn{3}{|c|}{ HEATER } & \multicolumn{3}{|c|}{ COOLER } \\
\hline$A\left(m^{2}\right)$ & Cost $(€)$ & $\begin{array}{c}\text { Annual cost } \\
\text { (€/year) }\end{array}$ & Energ (kw) & Cost $(€)$ & $\begin{array}{c}\text { Annual cost } \\
\text { (€/year) }\end{array}$ \\
\hline- & - & - & - & - & - \\
\hline- & - & - & - & - & - \\
\hline- & - & - & - & - & - \\
\hline 10,0 & 15862 & 2364 & 7,6 & 15051 & 2243 \\
\hline 27,4 & 66558 & 9919 & 23,0 & 64784 & 9655 \\
\hline \multicolumn{3}{|c|}{ HEAT EXCHANGER } & \multicolumn{3}{|c|}{ COMPRESSOR } \\
\hline$A\left(m^{2}\right)$ & Cost $(€)$ & $\begin{array}{c}\text { Annual cost } \\
\text { (€/year) }\end{array}$ & Energ (kw) & Cost $(€)$ & $\begin{array}{c}\text { Annual cost } \\
\text { (€/year) }\end{array}$ \\
\hline- & - & - & - & - & - \\
\hline- & - & - & - & - & - \\
\hline- & - & - & - & - & - \\
\hline 534,0 & 219997 & 32786 & 144,8 & 151439 & 22569 \\
\hline 1680,6 & 440206 & 65604 & 438,4 & 395890 & 58999 \\
\hline
\end{tabular}


Table A.2. Annual Energy Cost in all studied configuration (€/year)

\begin{tabular}{|c|c|c|c|c|c|c|}
\hline \multirow[b]{2}{*}{ Direct Dist } & & \\
\hline & 7465,1 & Water & 75982 & - & - & - \\
\hline Indirect Dist & - & - & - & 7690,6 & $\begin{array}{l}\text { Med Pres } \\
\text { Steam }\end{array}$ & 1817633 \\
\hline Petlyuk Dist & - & - & - & - & - & - \\
\hline Petlyuk Dist with VRC & - & - & - & - & - & - \\
\hline \multirow[t]{3}{*}{ Indirect Dist with VRC } & - & - & - & 7260,3 & $\begin{array}{l}\text { Med Pres } \\
\text { Steam }\end{array}$ & 1715935 \\
\hline & \multicolumn{3}{|c|}{ CONDENSER (Column 2) } & \multicolumn{3}{|c|}{ REBOILER (Column 2) } \\
\hline & Energy (kw) & Utility & $\begin{array}{c}\text { Annual cost } \\
\text { (€/year) }\end{array}$ & Energy (kw) & Utility & $\begin{array}{c}\text { Annual cost } \\
\text { (€/year) }\end{array}$ \\
\hline Direct Dist & 4543,6 & Water & 46246 & 12051,8 & $\begin{array}{l}\text { Med Pres } \\
\text { Steam }\end{array}$ & 2848379 \\
\hline Indirect Dist & 11878,1 & Water & 120899 & 4212,2 & $\begin{array}{l}\text { Med Pres } \\
\text { Steam }\end{array}$ & 995522 \\
\hline Petlyuk Dist & 8772,0 & Water & 89284 & 8825,7 & $\begin{array}{l}\text { Med Pres } \\
\text { Steam }\end{array}$ & 2085902 \\
\hline Petlyuk Dist with VRC & 7230,6 & Water & 73595 & 7227,1 & $\begin{array}{c}\text { Med Pres } \\
\text { Steam }\end{array}$ & 1708072 \\
\hline \multirow[t]{3}{*}{ Indirect Dist with VRC } & 7465,1 & Water & 75982 & - & - & - \\
\hline & \multicolumn{3}{|c|}{ HEATER } & \multicolumn{3}{|c|}{ COOLER } \\
\hline & Energy (kw) & Utility & $\begin{array}{c}\text { Annual cost } \\
\text { (€/year) }\end{array}$ & Energy (kw) & Utility & $\begin{array}{c}\text { Annual cost } \\
\text { (€/year) }\end{array}$ \\
\hline Direct Dist & - & - & - & - & - & - \\
\hline Indirect Dist & - & - & - & - & - & - \\
\hline Petlyuk Dist & - & - & - & - & - & - \\
\hline Petlyuk Dist with VRC & 298,5 & $\begin{array}{l}\text { High Pres } \\
\text { Steam }\end{array}$ & 84378 & 338,1 & Water & 3441 \\
\hline \multirow[t]{3}{*}{ Indirect Dist with VRC } & 832,6 & $\begin{array}{l}\text { High Pres } \\
\text { Steam }\end{array}$ & 235314 & 1030,9 & Water & 10493 \\
\hline & \multicolumn{3}{|c|}{ COMPRESSOR } & & & \\
\hline & Energy (kw) & Utility & $\begin{array}{c}\text { Annual cost } \\
\text { (€/year) }\end{array}$ & & & \\
\hline Direct Dist & - & - & - & & & \\
\hline Indirect Dist & - & - & - & & & \\
\hline Petlyuk Dist & - & - & - & & & \\
\hline Petlyuk Dist with VRC & 144,8 & Electricity & 69368 & & & \\
\hline Indirect Dist with VRC & 438,4 & Electricity & 210097 & & & \\
\hline
\end{tabular}

Table A.3. Total Annual Cost in all studied configuration ( $€ /$ year)

\begin{tabular}{lc|c|c} 
& \multicolumn{3}{|c}{ TOTAL COST } \\
\cline { 2 - 4 } & Capital Cost (€/year) & Energy Cost (€/year) & Total Annual Cost (€/year) \\
\cline { 2 - 4 } Direct Dist & 320019 & 2970608 & 3290627 \\
Indirect Dist & 300525 & 2934054 & 3234579 \\
Petlyuk Dist & 295716 & 2175186 & 2470901 \\
Petlyuk Dist with VRC & 332104 & 1938855 & $\mathbf{2 2 7 0 9 5 9}$ \\
Indirect Dist with VRC & 422597 & 2247821 & 2670418
\end{tabular}


A.2 Results of example 4.2 "Cold recovery configuration (excess of vapor stream in enrichment section)"

Table A.4. Annual Capital Cost in all studied configuration (€/year)

Direct Dist

Indirect Dist

Petlyuk Dist

Petlyuk Dist with VRC

Indirect Dist with VRC

Direct Dist

Indirect Dist

Petlyuk Dist

Petlyuk Dist with VRC

Indirect Dist with VRC

Direct Dist

Indirect Dist

Petlyuk Dist

Petlyuk Dist with VRC

Indirect Dist with VRC

Direct Dist

Indirect Dist

Petlyuk Dist

Petlyuk Dist with VRC

6844,1

1474823

Indirect Dist with VRC

\begin{tabular}{|c|c|c|c|c|c|}
\hline \multicolumn{6}{|c|}{ CAPITAL COST } \\
\hline \multicolumn{6}{|c|}{ COLUMNS } \\
\hline \multicolumn{3}{|c|}{ Column 1} & \multicolumn{3}{|c|}{ Column 2} \\
\hline$V\left(m^{3}\right)$ & Cost $(€)$ & $\begin{array}{c}\text { Annual cost } \\
\text { (€/year) }\end{array}$ & $V\left(m^{3}\right)$ & Cost $(€)$ & $\begin{array}{c}\text { Annual cost } \\
\text { (€/year) }\end{array}$ \\
\hline 199,3 & 1733135 & 258288 & 72,8 & 835298 & 124484 \\
\hline 68,0 & 732040 & 109096 & 268,7 & 2490896 & 371217 \\
\hline 49,6 & 521794 & 77763 & 287,4 & 2941774 & 438411 \\
\hline 49,6 & 521794 & 77763 & 257,7 & 2354008 & 350817 \\
\hline 68,0 & 732040 & 109096 & 261,0 & 2686405 & 400354 \\
\hline \multicolumn{3}{|c|}{ CONDENSER (Column 1) } & \multicolumn{3}{|c|}{ REBOILER (Column 1) } \\
\hline$A\left(m^{2}\right)$ & Cost $(€)$ & $\begin{array}{c}\text { Annual cost } \\
\text { (€/year) }\end{array}$ & $A\left(m^{2}\right)$ & Cost $(€)$ & $\begin{array}{c}\text { Annual cost } \\
\text { (€/year) }\end{array}$ \\
\hline 1546,6 & 419777 & 62559 & - & - & - \\
\hline- & - & - & 586,6 & 219153 & 32660 \\
\hline- & - & - & - & - & - \\
\hline- & - & - & - & - & - \\
\hline- & - & - & 588,3 & 219530 & 32716 \\
\hline \multicolumn{3}{|c|}{ CONDENSER (Column 2) } & \multicolumn{3}{|c|}{ REBOILER (Column 2) } \\
\hline$A\left(m^{2}\right)$ & Cost $(€)$ & $\begin{array}{c}\text { Annual cost } \\
\text { (€/year) }\end{array}$ & $A\left(m^{2}\right)$ & Cost $(€)$ & $\begin{array}{c}\text { Annual cost } \\
\text { (€/year) }\end{array}$ \\
\hline 912,4 & 289843 & 43195 & 847,2 & 276035 & 41137 \\
\hline 2215,5 & 552593 & 82353 & 921,8 & 291827 & 43491 \\
\hline 1804,0 & 471174 & 70219 & 817,1 & 269591 & 40177 \\
\hline 1168,5 & 343114 & 51134 & 512,7 & 202340 & 30155 \\
\hline 1623,5 & 435186 & 64856 & - & - & - \\
\hline \multicolumn{3}{|c|}{ HEAT EXCHANGER } & \multicolumn{3}{|c|}{ COMPRESSOR } \\
\hline$A\left(m^{2}\right)$ & Cost $(€)$ & $\begin{array}{c}\text { Annual cost } \\
\text { (€/year) }\end{array}$ & Energ (kw) & Cost (€) & $\begin{array}{c}\text { Annual cost } \\
\text { (€/year) }\end{array}$ \\
\hline- & - & - & - & - & - \\
\hline- & - & - & - & - & - \\
\hline- & - & - & - & - & - \\
\hline 6844,1 & 1474823 & 219792 & 1364,9 & 946032 & 140987 \\
\hline 8886,3 & 1899397 & 283066 & 1658,5 & 1085927 & 161835 \\
\hline
\end{tabular}


Table A.5. Annual Energy Cost in all studied configuration (€/year)

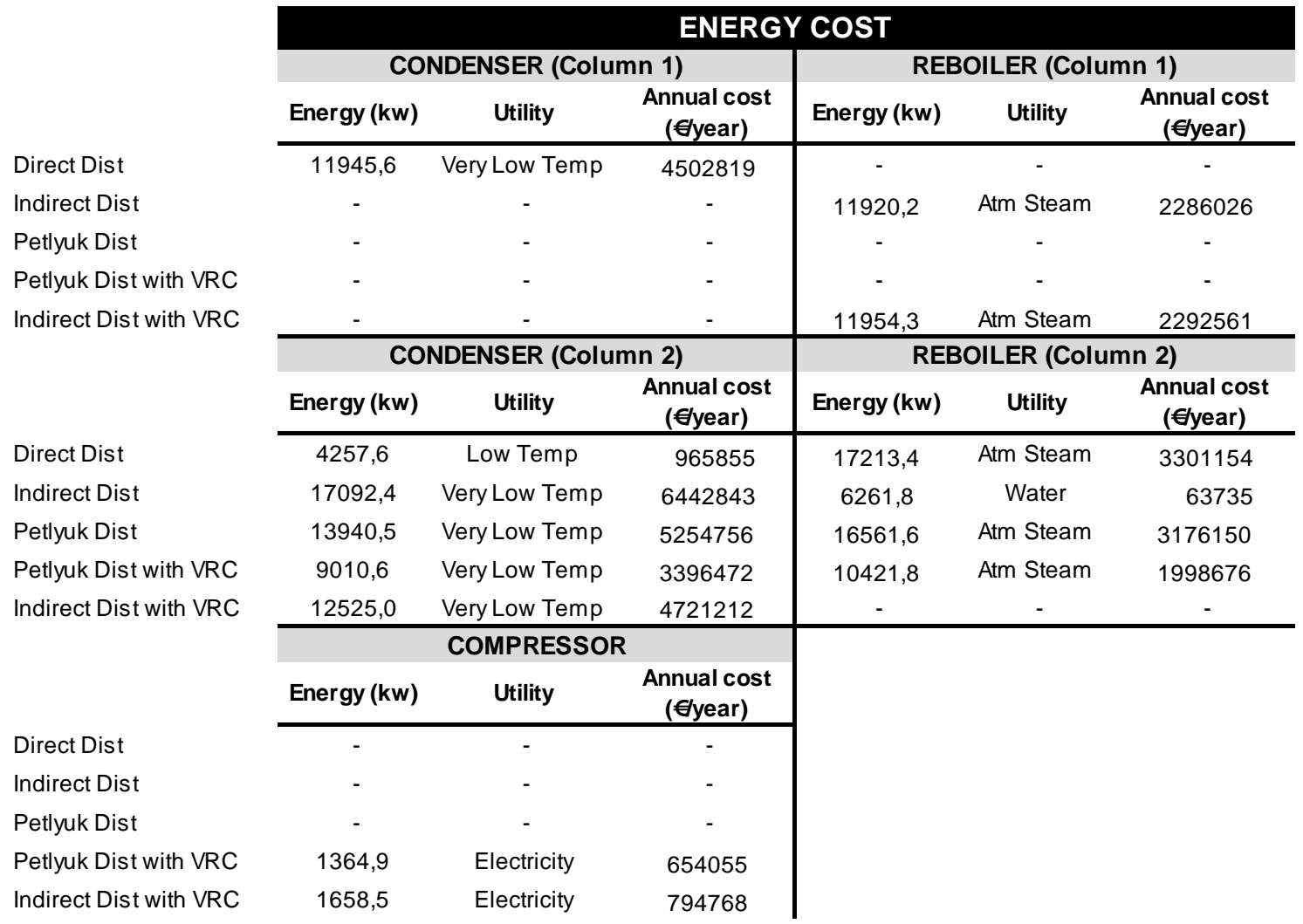

Table A.6. Total Annual Cost in all studied configuration (€/year)

Direct Dist

Indirect Dist

Petlyuk Dist

Petlyuk Dist with VRC

Indirect Dist with VRC

\begin{tabular}{c|c|c}
\hline \multicolumn{3}{c|}{ TOTAL COST } \\
\hline Capital Cost (€/year) & Energy Cost (€/year) & Total Annual Cost (€/year) \\
\hline 529664 & 8769829 & 9299493 \\
638816 & 8792604 & 9431420 \\
626570 & 8430906 & 9057476 \\
870647 & 6049203 & 6919850 \\
1051922 & 7808540 & 8860463
\end{tabular}




\section{BIBLIOGRAPHY}

Caballero, J. A. and I. E. Grossmann (2006). "Structural Considerations and Modeling in the Synthesis of Heat-Integrated-Thermally Coupled Distillation Sequences." Industrial \& Engineering Chemistry Research 45(25): 8454-8474.

Carlberg, N. A. and A. W. Westerberg (1989). "Temperature-heat diagrams for complex columns. 2. Underwood's method for side strippers and enrichers." Industrial \& Engineering Chemistry Research 28(9): 1379-1386.

Carlberg, N. A. and A. W. Westerberg (1989). "Temperature-heat diagrams for complex columns. 3. Underwood's method for the Petlyuk configuration." Industrial \& Engineering Chemistry Research 28(9): 1386-1397.

De Koeijer, G. and S. Kjelstrup (2000). "Minimizing entropy production rate in binary tray distillation." Int. J. Applied Thermodynamics 3(3): 105-110.

EIA (2011). International Energy Outlook 2011: With Projections to 2035. E. I. A. (U.S.), Bernan Assoc: p.292.

Engelien, H. K. and S. Skogestad (2004). "Selecting appropriate control variables for a heat-integrated distillation system with prefractionator." Computers \&amp; Chemical Engineering 28(5): 683-691.

Fidkowski, Z. T. and R. Agrawal (2001). "Multicomponent thermally coupled systems of distillation columns at minimum reflux." AIChE Journal 47(12): 2713-2724.

Halvorsen, I. J. and S. Skogestad (2003). "Minimum Energy Consumption in Multicomponent Distillation. 3. More Than Three Products and Generalized Petlyuk Arrangements." Industrial \& Engineering Chemistry Research 42(3): 616-629.

Humphrey, J. L. (1995). "Separation processes: Playing a critical role." Journal Name: Chemical Engineering Progress; Journal Volume: 91; Journal Issue: 10; Other Information: PBD: Oct 1995: Medium: X; Size: pp. 31-41.

Humphrey, J. L., A. F. Seibert, et al. (1991). Separation technologies: Advances and priorities: Medium: X; Size: Pages: (226 p).

Humphrey, J. L. and A. F. Siebert (1992). "Separation technologies; An opportunity for energy savings." Journal Name: Chemical Engineering Progress; (United States); Journal Volume: 88:3: Medium: X; Size: Pages: 32-42.

Jana, A. K. (2010). "Heat integrated distillation operation." Applied Energy 87(5): 14771494.

Mix, T. W., J. S. Dueck, et al. (1978). "Energy Conservation in Distillation." Chemical Engineering Progress 74: 1949-1955.

Navarro, M. A., J. Javaloyes, et al. (2012). "Strategies for the robust simulation of thermally coupled distillation sequences." Computers \&amp; Chemical Engineering 36(0): 149-159.

Petlyuk, F. B., V. M. Platonov, et al. (1965). "Thermodynamically Optimal Method For Separating Multicomponent Mixtures." International Chemical Engineering 5(3): 555.

Ruud, H. (1992). "Thermal Coupling for Energy Efficiency." Suplement to the Chem. Eng. S14.

Smith, R. (2005). Chemical process design and integration, Wiley.

Turton, R., R. C. Bailie, et al. (2008). Analysis, Synthesis and Design of Chemical Processes, Pearson Education. 